\title{
Adherence to disease-modifying therapies in patients with multiple sclerosis
}

This article was published in the following Dove Press journal:

Patient Preference and Adherence

\section{Aleksandra Kołtuniuk Joanna Rosińczuk}

Department of Nervous System Diseases, Faculty of Health Sciences, Wroclaw Medical University, Wroclaw, Poland
Correspondence: Aleksandra Kołtuniuk Department of Nervous System Diseases, Faculty of Health Sciences, Wroclaw Medical University, 5 Bartla Street, 5I-6|8 Wroclaw, Poland

Tel +48 $7 \quad 1784 \quad 1805$

Fax +48 7 I $34 \mid 9533$

Email aleksandra.koltuniuk@umed. wroc.pl
Background: Multiple sclerosis (MS) is a chronic, inflammatory progressive demyelinating disease of the central nervous system. MS is one of the main causes of disability among young adults, and its management is a serious challenge for the healthcare system.

Purpose: The main purpose of this study was to examine adherence to first-line diseasemodifying therapy (DMT) in MS patients using the self-report Multiple Sclerosis Treatment Adherence Questionnaire (MS-TAQ).

Materials and methods: The participants consisted of 226 MS patients (166 women and 60 men) who were treated with first-line immunomodulatory DMT. This study used a questionnaire designed by the authors, which contained questions about sociodemographic data, and the Polish version of the MS-TAQ.

Results: The overall adherence was $76.5 \%$ according to the first criterion (missed $\geq 1$ injection or tablet). There were no statistically significant differences due to sociodemographic variables between adherent and nonadherent patients. However, patients taking Avonex ${ }^{\circledR}$ significantly more often belonged to the adherent group $(P=0.042)$. The most frequently mentioned reasons why nonadherent patients forget to take the drug included the following: too busy in their daily activities, indisposition to take the drug, unwillingness to take the drug, interference with daily activities, and dissatisfaction with the drug. The degree of adherence among MS patients treated with immunomodulatory drugs is high; however, some patients do not take medications regularly.

Conclusion: Due to the utility of the MS-TAQ, the caregivers of MS patients are able to quickly and easily assess the occurrence of side effects, ways to cope with them, and the occurrence of barriers to taking medication.

Keywords: multiple sclerosis, treatment adherence, disease-modifying therapy, side effects, Multiple Sclerosis Treatment Adherence Questionnaire

\section{Introduction}

Multiple sclerosis (MS) is a chronic, inflammatory progressive demyelinating disease of the central nervous system. There is a global latitude gradient in MS prevalence; in Europe, the prevalence rate is 100/100,000 inhabitants, whereas in Eastern Asia and Sub-Saharan Africa, it is 2/100,000. ${ }^{1}$ In Poland, on the basis of cohort studies, it is estimated that the prevalence rate is $149.8 / 100,000$ for women and 66.5/100,000 for men $(109 / 100,000$ for the entire population $){ }^{2}$

The first symptoms of the disease typically appear in young adults between 20 and 40 years of age; these are mainly visual disturbances and difficulties in movement. ${ }^{3}$ Due to the physical consequences of the disease, MS is one of the main causes of disability among young adults, and its management is a serious challenge for healthcare systems. ${ }^{4}$ Disease-modifying therapies (DMTs) constitute the current first-line treatment option 
for relapsing-remitting and secondary progressive MS because they reduce the relapse rate and slow disability progression. ${ }^{5}$

Currently, the first-line drugs include interferon beta-1a (Avonex $^{\circledR}$ [Biogen Manufacturing ApS, Hillerød, Denmark], which is injected intramuscularly once a week, and Rebif ${ }^{\circledR}$ [Merck Serono S.p.A., Bari, Italy], which is injected subcutaneously three times a week), interferon beta-1b (Betaferon ${ }^{\circledR}$ [Bayer AG, Berlin, Germany] and Extavia ${ }^{\circledR}$ [Novartis Pharma GmbH, Nürnberg, Germany], which are injected subcutaneously every other day), glatiramer acetate (Copaxone $^{\circledR}$ [Teva Pharmaceuticals Europe B.V., Haarlem, the Netherlands], which is injected subcutaneously every day or three times a week), and dimethyl fumarate (Tecfidera ${ }^{\circledR}$ [Biogen Manufacturing ApS], which is taken orally twice a day). However, in order to achieve the intended therapeutic effect in the form of reducing the number of relapses, slowing down the progression of the disease, and reducing disability and the number of hospitalizations, the patient must follow the treatment recommendations, such as taking the drug according to the prescribed dosage and for the complete duration of the treatment. ${ }^{6-8}$

WHO data indicate that only half of patients suffering from chronic diseases adhere to treatment recommendations. ${ }^{9}$ Recent studies on MS patients have shown that the percentage of people who strictly adhere to treatment recommendations varies from $49 \%{ }^{10}$ to $93 \%{ }^{6}$ This variation is most likely associated with the use of various research methods and adherence level criteria. Thus far, adherence levels have not been satisfactorily defined. However, previous studies have indicated that a level of adherence above $80 \%$ can be considered optimal because adherence at this level significantly reduces the risk of hospitalization and acute medical visits ${ }^{11,12}$ and total expenditures for the management of MS patients. ${ }^{12}$

MS patients do not follow treatment recommendations for a wide range of reasons. ${ }^{10,13}$ The most important ones include occurrence of side effects, ${ }^{5,14,15}$ lack of therapeutic effectiveness, ${ }^{16}$ and forgetting to take a dose of the drug. $., 6,15$ It should be emphasized that the duration of therapy also plays an important role. ${ }^{6}$ Studies have shown that two years after starting therapy, only $30 \%-40 \%$ of patients follow treatment recommendations. ${ }^{17,18}$ It should be noted that sociodemographic factors may also significantly influence compliance; for example, people with lower economic status are characterized by lower adherence. ${ }^{8}$

In Poland, no study has assessed adherence levels among MS patients. Thus, the aim of this study was to examine adherence to first-line DMT in MS patients using the selfreport Multiple Sclerosis Treatment Adherence Questionnaire (MS-TAQ).

\section{Materials and methods Study design and participants}

A cross-sectional descriptive design with a questionnaire survey was used. The study was conducted in 2017 among $226 \mathrm{MS}$ patients (166 women and 60 men) with a mean age of $37.3 \pm 9.68$ years. All patients were treated with first-line DMT at four neurological centers in Wroclaw, Poland. Patients who met inclusion criteria filled the questionnaires during control visit in neurological center (when they get their medicine for the next month).

\section{Qualification criteria}

Inclusion criteria were 1) a confirmed diagnosis of relapsingremitting MS (RR-MS) based on medical records, 2) taking first-line DMT drugs (Avonex, Rebif, Betaferon, Extavia, Copaxone, or Tecfidera), 3) treatment for at least six months prior to participation in the study, 4) age over 18 years, and 5 ) written informed consent prior to participation in the study. Exclusion criteria were 1) progressive forms of MS, 2) confirmed diagnosis of RR-MS but not taking first-line DMT drugs (Avonex, Rebif, Betaferon, Extavia, Copaxone, or Tecfidera), 3) treatment initiated less than six months before participation in the study, 4) severe cognitive impairment (patients unable to follow the test instructions), and 5) lack of written consent to participate in the study.

\section{Instruments}

For the purposes of this study, the diagnostic survey method was applied, with the use of both a questionnaire designed by the author and the Polish version of MS-TAQ. ${ }^{19}$ The author's questionnaire was an original survey that included questions about sociodemographic data, that is, age, sex, place of residence, education, marital status, financial status, and duration of illness.

The MS-TAQ questionnaire is a self-administered tool to identify barriers to adherence for MS patients taking DMTs. The MS-TAQ questionnaire contains 30 questions in three subscales, each with a different response format: DMT-Barriers (DMT-BARR) quantify the extent to which the patient rated 13 barriers to adherence as important reasons for nonadherence (asked only of patients who missed at least one dose in the previous 28 days; rated on a four-point scale ranging from "not important at all" to "extremely important" with respect to missing or forgetting a dose); DMT-Side Effects (DMT-SE) describe the frequency of 10 side effects (asked of all patients; rated on a five-point scale from "never" to "all or nearly all of the time"); and DMT-Coping Strategies (DMT-COPE) assess seven coping mechanisms used by the patient to reduce side effects (eg, using an ice cube on the 
injection site; asked of all patients; binary yes/no response for "in the past four weeks [28 days] did you usually"). ${ }^{10}$

\section{Definition of adherence}

In previous studies that used the MS-TAQ instrument, patients were identified as nonadherent if they missed one or more dose in the 28 days prior to completing the survey ${ }^{10}$ or if they missed at least $25 \%$ of the chosen DMT doses, that is, if they missed $\geq 1$ injection of Avonex; $\geq 3$ injections of Rebif, Betaferon, Extavia, or Copaxone $40 \mathrm{mg}$; or $\geq 7$ injections of Copaxone $20 \mathrm{mg} .{ }^{7}$ In this study, nonadherent patients also included those taking Tecfidera who missed two or more tablets (the first criterion) or missed more than 14 tablets in one month (the second criterion).

\section{Data analysis}

Statistical analysis was performed using Statistica 13 (StatSoft, Dell Inc., Tulsa, OK, USA) under the license of Wroclaw Medical University, Poland. For the measurable variables, the arithmetic mean (X) and SD were calculated, and for nonmeasurable variables, the percentages (\%) were calculated. All quantitative variables were tested using the Shapiro-Wilk test to determine the type of distribution. The nonparametric Mann-Whitney $U$ test was used to compare the results between groups for continuous variables, and the chi-squared test was used for categorical data. For all comparisons, the level of $\alpha=0.05$ was assumed, and the obtained $P$-values were rounded to four decimal places.

Internal reliability of Polish version of MS-TAQ questionnaire was calculated using Cronbach's alpha coefficient that was 0.57 for DMT-COPE, 0.89 for DMT-BARR, and 0.90 for DMT-SE, indicating that the scale had acceptable reliability.

\section{Results}

The study was conducted among 226 patients (166 women and 60 men) with a mean age of $37.3 \pm 9.68$ years (range 19-64 years) treated with immunomodulatory first-line DMT, in the form of either an injection or a tablet. The largest group of respondents were people who lived in urban areas $(72.8 \%)$, who were married (57.5\%), who were professionally active (71\%), who had completed a degree in higher education (54.4\%), who assessed their socioeconomic status as average $(76.5 \%)$, and who had suffered from MS for 6-10 years (36.2\%). Analysis of the data showed that MS patients complain about the occurrence of many different symptoms, most often fatigue (61.9\%) and movement disorders (55.3\%).

Among the patients, $25.2 \%$ took the drug every day, $42.4 \%$ every other day, $13.2 \%$ three times a week, and $19.0 \%$ once a week. In the group of people taking the drug as an injection, the vast majority performed the injection themselves (68\%), whereas $13.1 \%$ had been assisted by other people several times and $11.6 \%$ always or almost always needed help.

The overall adherence in our sample was $76.5 \%$ according to the first criterion (missed $\geq 1$ injection or tablet) and $95.6 \%$ according to the second criterion (missed $\geq 25 \%$ injections or tablets). Only 10 patients missed $\geq 25 \%$ of injections according to the second criterion. This group was too small, so we used the criterion of missing $\geq 1$ injection in the subsequent analysis. Regarding sociodemographic variables, there were no statistically significant differences between adherent and nonadherent patients (Table 1).

However, taking into account the reported symptoms, it was found that dysphagia was more common in the nonadherent group ( $P=0.0113$ ) (Figure 1). It was also shown that in the group of patients who took drugs orally, all were in the adherent group, whereas in the group of people taking drugs via injection, patients using Avonex significantly more often belonged to the adherent group $(P=0.042)$ and patients using Betaferon significantly more often belonged to the nonadherent group ( $P=0.012$ ) (Figure 2). Among the patients in the injection group, $60.0 \%$ used an autoinjection device and $22.5 \%$ injected the drug manually. It was also demonstrated that people who injected in the traditional way (manually) were nonadherent significantly more often than those who took pills or used autoinjectors $(P=0.0026)$.

Among the reasons why nonadherent patients forgot to take the drug, the most often mentioned were too many daily activities, indisposition to take the drug, unwillingness to take the drug, taking the drug interfered with daily activities, and dissatisfaction with the drug (Table 2).

The analysis did not show statistically significant differences between the adherent and nonadherent group with respect to the average score on the DMT-SE domain (SD adherence $=13.02, \mathrm{SD}$ nonadherence $=14.45, P=0.30$ ) and the DMT-COPE domain $(\mathrm{SD}$ adherence $=1.30, \mathrm{SD}$ nonadherence $=1.39, P=0.54)$ of the MS-TAQ. However, the analysis of each question showed that in the DMT-SE domain, nonadherent patients significantly more frequently reported the presence of swelling, welts, or lumps at the injection site $(P=0.0165)$ as well as abnormal redness of the skin or rash at the injection site $(P=0.0106)$ after drug administration compared with adherent patients (Table 3 ).

In turn, in the DMT-COPE domain, nonadherent patients significantly more often massaged the injection site afterward to reduce swelling or itching $(P=0.0346)$ than adherent patients (Table 4).

It was also shown that almost half of the patients (47.3\%) believed that taking the current drug according to the doctor's 
Table I Characteristics of the study participant regarding the adherence to treatment recommendations

\begin{tabular}{|c|c|c|c|c|c|}
\hline \multirow[t]{2}{*}{ Characteristics } & \multicolumn{2}{|l|}{ Adherent } & \multicolumn{2}{|c|}{ Nonadherent } & \multirow[t]{2}{*}{$P$-value } \\
\hline & $\mathbf{M} \pm \mathbf{S D}$ & Me; min-max & $\mathbf{M} \pm \mathbf{S D}$ & Me; min-max & \\
\hline \multirow[t]{2}{*}{ Age } & $37.59 \pm 9.96$ & $37 ; 19-60$ & $36.43 \pm 8.70$ & $37 ; 19-59$ & $0.625^{a}$ \\
\hline & \multicolumn{2}{|c|}{ Adherent (\%) } & \multicolumn{2}{|c|}{ Nonadherent (\%) } & \\
\hline $\begin{array}{l}\text { Sex } \\
\quad \text { Female } \\
\text { Male }\end{array}$ & $\begin{array}{l}75.14 \\
24.86\end{array}$ & & $\begin{array}{l}67.92 \\
32.08\end{array}$ & & $0.297^{b}$ \\
\hline $\begin{array}{l}\text { Residence } \\
\text { Village } \\
\text { City }<100,000 \\
\text { City } 100,000-500,000 \\
\text { City }>500,000\end{array}$ & $\begin{array}{l}25 \\
21.5 \mid \\
14.53 \\
38.95 \\
\end{array}$ & & $\begin{array}{l}33.96 \\
22.64 \\
5.66 \\
37.74 \\
\end{array}$ & & $0.283^{b}$ \\
\hline $\begin{array}{l}\text { Marital status } \\
\text { Married } \\
\text { Single } \\
\text { Widowed }\end{array}$ & $\begin{array}{l}56.07 \\
41.62 \\
2.31 \\
\end{array}$ & & $\begin{array}{l}62.26 \\
35.85 \\
1.89\end{array}$ & & $0.726^{\mathrm{b}}$ \\
\hline $\begin{array}{l}\text { Education } \\
\text { Primary } \\
\text { Secondary } \\
\text { Higher } \\
\end{array}$ & $\begin{array}{l}11.56 \\
31.79 \\
56.65\end{array}$ & & $\begin{array}{l}9.43 \\
43.40 \\
41.17\end{array}$ & & $0.298^{b}$ \\
\hline $\begin{array}{l}\text { Professional activity } \\
\text { Blue-collar worker } \\
\text { White-collar worker } \\
\text { Annuitant } \\
\text { Student } \\
\text { Unemployed }\end{array}$ & $\begin{array}{l}12.14 \\
58.38 \\
19.08 \\
5.20 \\
5.20 \\
\end{array}$ & & $\begin{array}{l}16.98 \\
56.60 \\
15.09 \\
9.43 \\
1.89 \\
\end{array}$ & & $0.513^{b}$ \\
\hline $\begin{array}{l}\text { Socioeconomic status } \\
\text { Low } \\
\text { Medium } \\
\text { High }\end{array}$ & $\begin{array}{l}16.76 \\
76.88 \\
6.36 \\
\end{array}$ & & $\begin{array}{l}15.09 \\
75.47 \\
9.43 \\
\end{array}$ & & $0.732^{b}$ \\
\hline $\begin{array}{l}\text { Disease duration } \\
\qquad 1 \text { year } \\
\text { I-5 years } \\
6-10 \text { years } \\
>10 \text { years }\end{array}$ & $\begin{array}{l}4.62 \\
33.53 \\
33.53 \\
28.32\end{array}$ & & $\begin{array}{l}3.77 \\
22.64 \\
45.28 \\
28.30\end{array}$ & & $0.367^{b}$ \\
\hline
\end{tabular}

Notes: aMann-Whitney $U$ test. ${ }^{\text {b } C h i-s q u a r e d ~ t e s t . ~}$

Abbreviations: M, mean; max, maximum; Me, median, min, minimum.

recommendations was unusually easy for them, whereas for $18.5 \%$ of respondents, it was moderately difficult. Only one person stated that it was extremely difficult to adhere to taking the drug in accordance with the doctor's instructions. Half of the patients stated that they were very or fully satisfied with their treatment; however, 11 patients were not satisfied or were only slightly satisfied with their MS treatment. With respect to the degree of patient satisfaction, there were no statistically significant differences between the adherent and nonadherent groups $(P=0.1196)$.

\section{Discussion}

The issue of treatment adherence among patients with MS is widely discussed in scientific research. Many researchers have attempted to identify the key factors that influence noncompliance with treatment recommendations in this group of patients. ${ }^{6,14,15,18}$ Our study is the first performed in Poland to assess the level of adherence among MS patients treated with first-line immunomodulatory drugs. Previous studies have indicated that the percentage of people referred to as nonadherents (if they have completed 1 day or 28 days prior to completing the survey) ranged from $49 \%{ }^{10}$ to $85.4 \%{ }^{5}$ However, taking into account the medication possession ratio criterion, which is a percentage calculated from the number of doses dispensed in relation to the dispensing period of time, ${ }^{20}$ the percentage of adherents varied from $39.9 \%{ }^{17}$ to $78 \% .{ }^{13}$ Moreover, in studies using the index of proportion of days covered (calculated by dividing the number of days of DMT supplied by the number of days of observation), the percentage of adherents ranged from $58.58 \%$ for injection patients and $61.39 \%$ for oral patients ${ }^{12}$ to $76 \%$ after the first year of treatment. ${ }^{18}$ In the present study, the percentage of 


\section{MS symptoms (\%)}

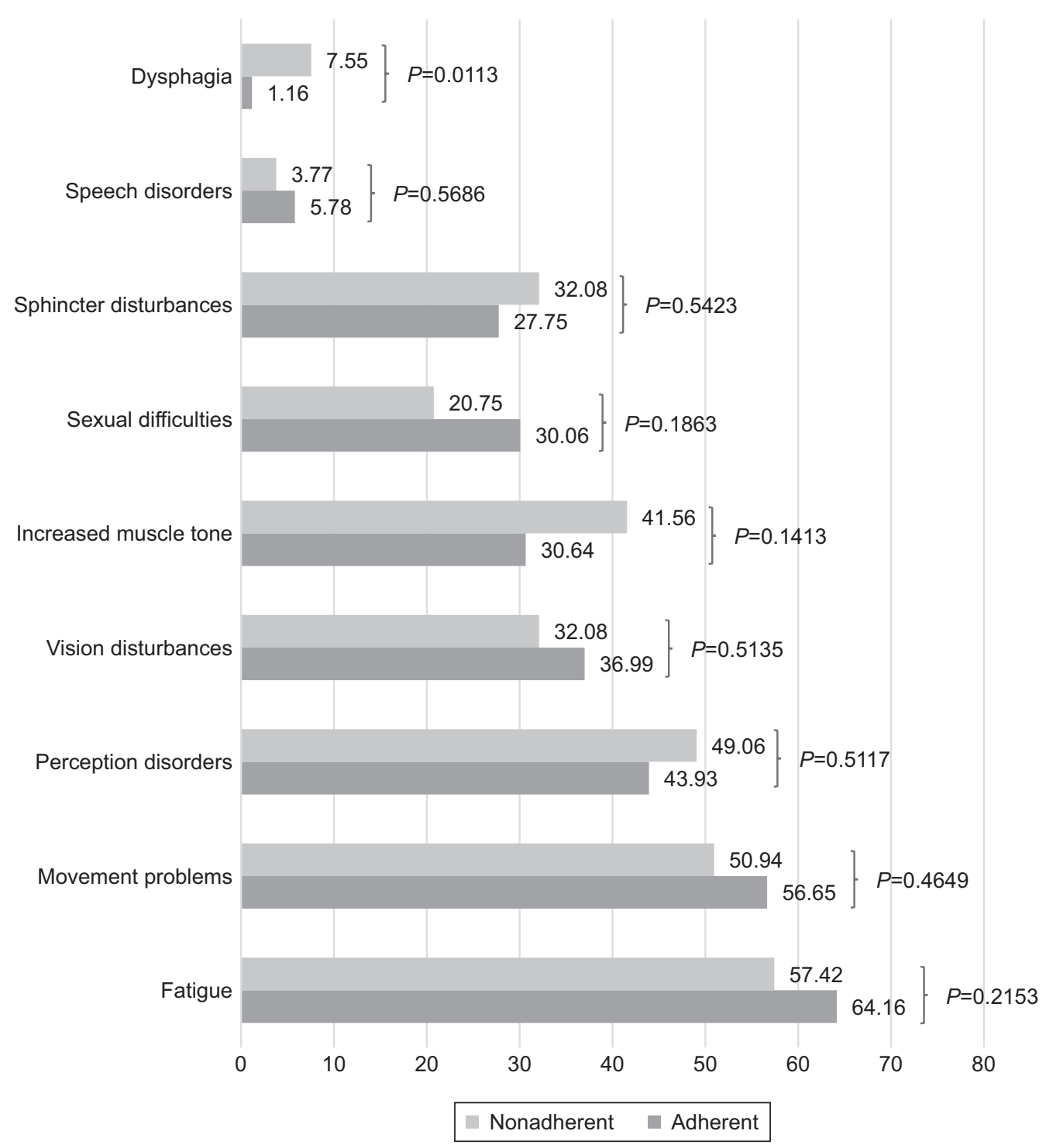

Figure I The occurrence of symptoms in MS patients. Abbreviation: MS, multiple sclerosis.

adherents was $76.5 \%$, which is similar to the results obtained by other researchers ${ }^{5-7,15}$ who used a self-report questionnaire to determine the number of adherent patients by adopting the criterion of assessing all doses in the previous month.

With respect to sociodemographic variables, the analysis showed no statistically significant differences between adherent and nonadherent patients, which is consistent with the results of Ožura et $\mathrm{al}^{7}$ and Wicks et al. ${ }^{10}$ However, according to Burks et al, ${ }^{12}$ women are $24 \%$ less likely to be adherent than men. Moreover, Higuera et $\mathrm{al}^{21}$ found that women had a $5.5 \%$ lower probability of being adherent than men. The lower level of adherence among women should prompt researchers to identify factors that will improve their adherence level, and it should prompt healthcare providers to give women more support because women represent the majority of MS patients. Decoo and Vokaer ${ }^{8}$ observed that patients with a lower intellectual capacity or from lower socioeconomic classes were more likely to exhibit poor treatment adherence. Devonshire et a $1^{15}$ concluded that adherent patients had a significantly shorter duration of disease than nonadherent patients, which was confirmed by McKay et al. ${ }^{13}$

In our study, $100 \%$ of the patients who received treatment in the form of tablets belonged to the adherent group, which is inconsistent with the data obtained by Burks et al, ${ }^{12}$ according to which only $61.4 \%$ of patients receiving oral therapy were adherent. This discrepancy may be due to the fact that oral therapy in the treatment of MS has been used in the USA for several years, and studies have confirmed that the 


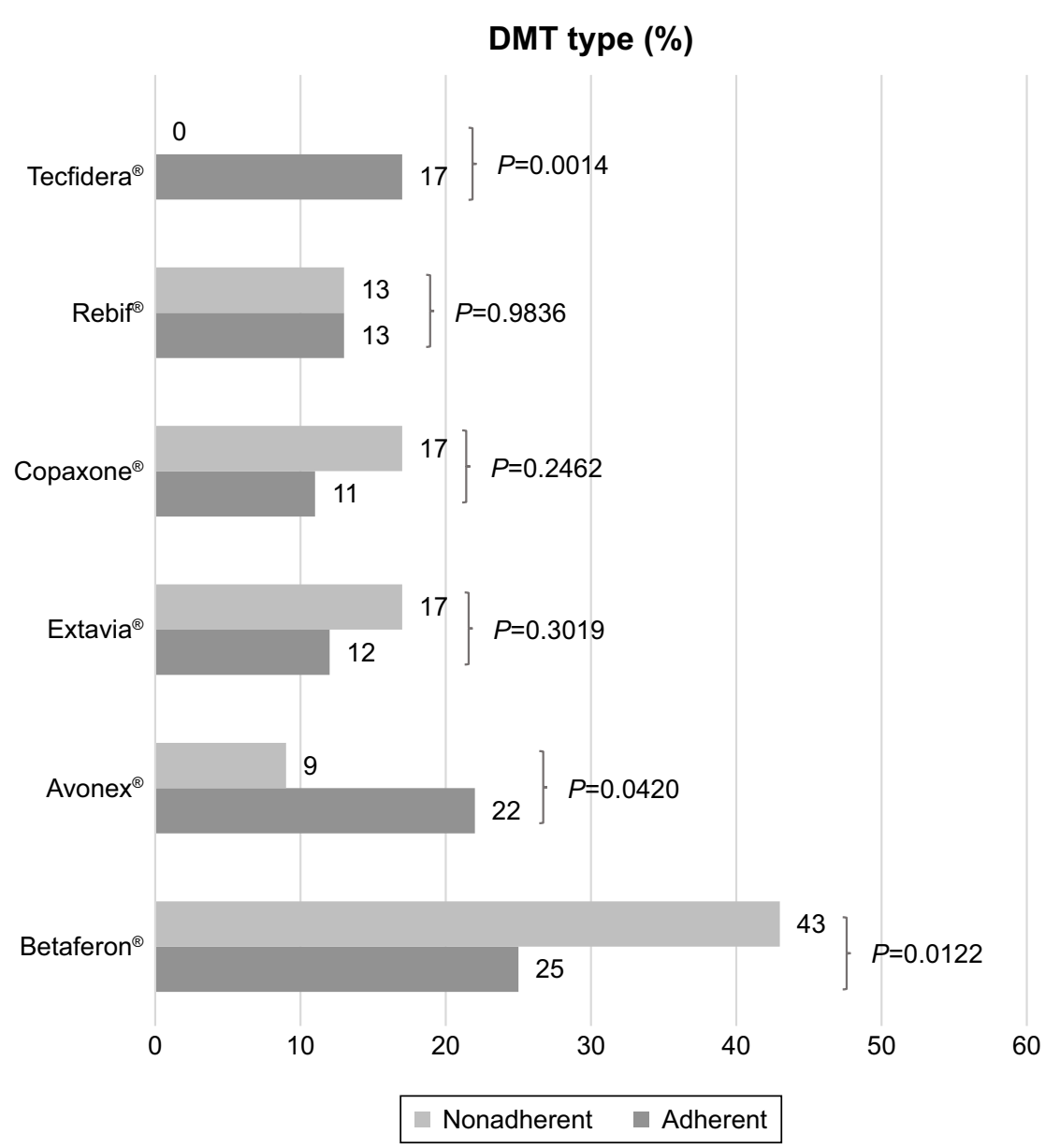

Figure 2 DMT type: Avonex ${ }^{\circledast}(\mathrm{N}=43)$, Betaferon ${ }^{\oplus}(\mathrm{N}=67)$, Copaxone $^{\oplus}(\mathrm{N}=28)$, Rebif ${ }^{\oplus}(\mathrm{N}=30)$, Extavia ${ }^{\oplus}(\mathrm{N}=29)$, and Tecfidera $^{\circledast}(\mathrm{N}=29)$. Abbreviation: DMT, disease-modifying therapy.

proportion of people regularly taking medication decreases with the duration of treatment. In Poland, oral therapy for MS is a relatively new form of treatment. The ease of taking tablets compared with injections is a great incentive to follow treatment recommendations. ${ }^{5,7,14,15,22}$ Moreover, it has been shown that people taking Avonex (once a week) significantly more often belong to the adherent group, which was confirmed in our study. This may be related to the fact that

Table 2 Reasons for missing injections in the nonadherent group (DMT-BARR)

\begin{tabular}{|c|c|c|c|c|c|c|c|c|c|c|}
\hline & \multicolumn{2}{|c|}{$\begin{array}{l}\text { Not } \\
\text { important } \\
\text { at all }\end{array}$} & \multicolumn{2}{|c|}{$\begin{array}{l}\text { A little } \\
\text { important }\end{array}$} & \multicolumn{2}{|c|}{$\begin{array}{l}\text { Moderately } \\
\text { important }\end{array}$} & \multicolumn{2}{|c|}{$\begin{array}{l}\text { Extremely } \\
\text { important }\end{array}$} & \multirow[t]{2}{*}{ Mean } & \multirow[t]{2}{*}{ SD } \\
\hline & $\mathbf{N}$ & $\%$ & $\mathbf{N}$ & $\%$ & $\mathbf{N}$ & $\%$ & $\mathbf{N}$ & $\%$ & & \\
\hline Memory problems & 23 & 43.39 & 9 & 16.98 & 11 & 20.75 & 10 & 18.86 & 1.15 & 1.18 \\
\hline Too busy & 15 & 28.30 & II & 20.75 & 18 & 33.96 & 9 & 16.98 & 1.39 & 1.08 \\
\hline Side effects of the injection & 26 & 49.05 & 7 & 13.20 & II & 20.75 & 9 & 16.98 & 1.05 & 1.18 \\
\hline Side effects of the medication & 23 & 43.39 & II & 20.75 & 10 & 18.86 & 9 & 16.98 & 1.09 & 1.14 \\
\hline Fear of needles & 31 & 58.49 & 8 & 15.09 & 8 & 15.09 & 6 & 11.32 & 0.79 & 1.08 \\
\hline Needing someone to help me take my medication & 39 & 73.58 & 7 & 13.20 & 7 & 13.02 & 0 & 0 & 0.39 & 0.71 \\
\hline Ran out of medication or could not refill my prescription & 40 & 75.47 & 0 & 0 & 6 & 11.32 & 7 & 13.20 & 0.62 & 1.13 \\
\hline I was away from home and not able to access my medication & 29 & 54.71 & 5 & 9.43 & 7 & 13.20 & 12 & 22.64 & 1.03 & 1.27 \\
\hline Feeling anxious, depressed, or nervous about taking my medication & 22 & 41.50 & 10 & 18.86 & 14 & 26.41 & 7 & 13.20 & 1.11 & 1.10 \\
\hline Dissatisfaction with my medication & 21 & 39.62 & 13 & 24.52 & 12 & 22.64 & 7 & 13.20 & 1.09 & 1.07 \\
\hline $\begin{array}{l}\text { I did not want taking my medication to interfere with my activities } \\
\text { or responsibilities }\end{array}$ & 20 & 37.73 & 16 & 30.18 & 7 & 13.20 & 10 & 18.86 & 1.13 & 1.12 \\
\hline Tired of taking my medication & 23 & 43.39 & 11 & 20.75 & 9 & 16.98 & 10 & 18.86 & 1.11 & 1.17 \\
\hline Did not feel like taking my medication & 19 & 35.84 & 14 & 26.41 & 12 & 22.64 & 8 & 15.09 & 1.16 & 1.08 \\
\hline
\end{tabular}

Abbreviations: DMT, disease-modifying therapy; DMT-BARR, DMT-Barriers. 

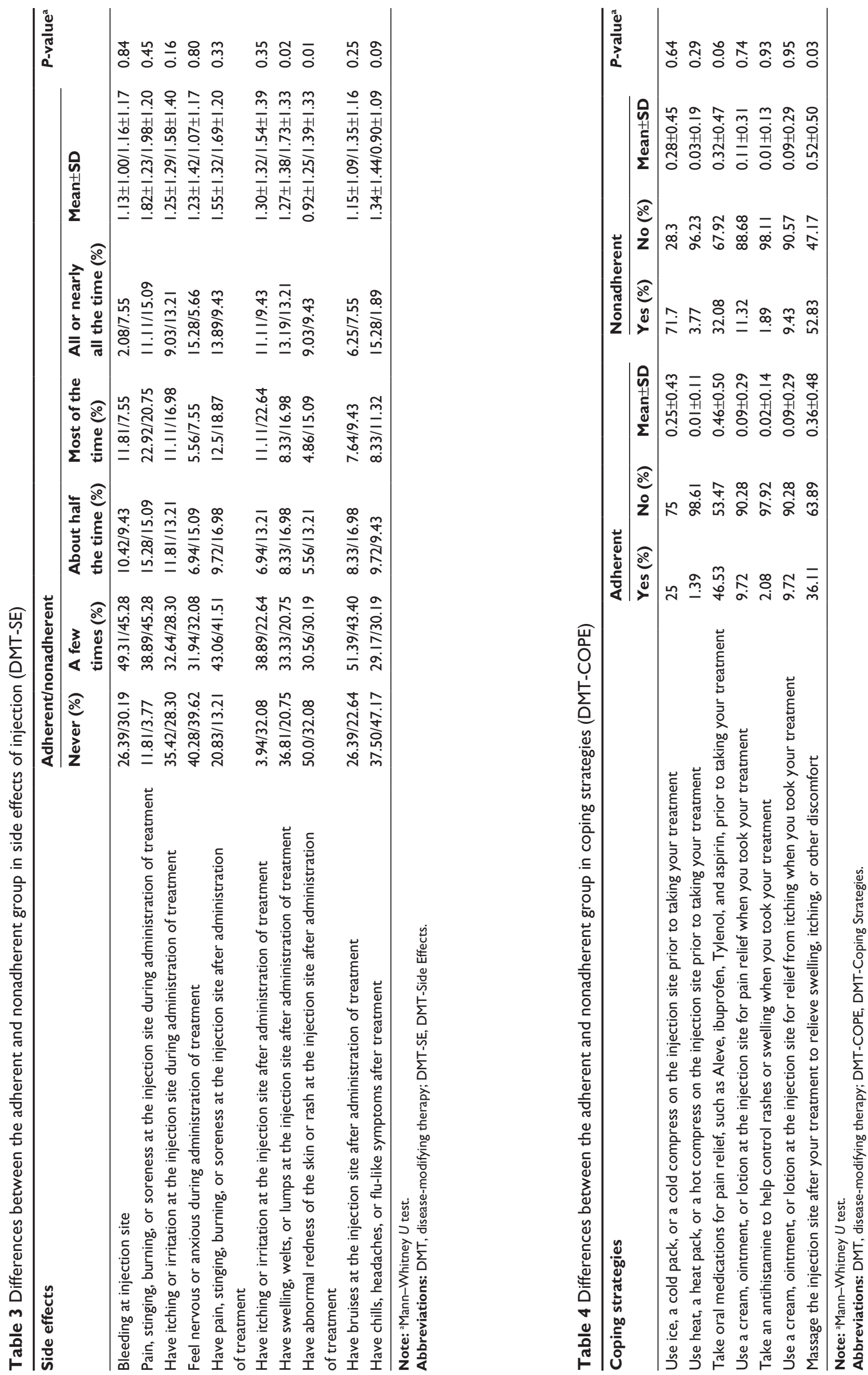
when a medication is used less often (and thus the difficulties associated with it are rarely experienced), it is easier to adhere to the therapeutic instructions.

The use of autoinjector devices to administer DMT has been shown to reduce the incidence of injection site reactions compared with manual injection. ${ }^{23}$ In the present study, it was shown that people using autoinjector devices to administer DMT were adherent significantly more frequently than people who injected in the traditional way (manually), which was not confirmed by Ožura et al. ${ }^{7}$

Our study found that dysphagia was a more common symptom in the nonadherent group $(P=0.0113)$. However, we suspect that dysphagia is not a driver of noncompliance. The studies conducted by Poorjavad et $\mathrm{al}^{24}$ and Fernandes et $\mathrm{al}^{25}$ showed that dysphagia was significantly more prevalent in patients with greater neurological disabilities as measured by Expanded Disability Status Scale scores and in patients with greater impairment of neurological functions. By contrast, nonadherent patients have more often been in a worse functional condition ${ }^{26}$ and had more neurological deficits, ${ }^{15}$ which may lead to more symptoms such as dysphagia among nonadherent patients.

Several authors ${ }^{5,6,15}$ have shown that forgetting to take a dose of medication is the main reason for being nonadherent. However, the side effects associated with injection (ie, pain, redness) and the tiredness associated with regular injections are also a significant problem. Admittedly, our study confirmed that nonadherent patients often do not follow treatment recommendations because of memory problems as well as side effects after the injection. The main reason for nonadherence was being too busy, which was confirmed by Ožura et al. ${ }^{7}$

Previous studies ${ }^{7,10}$ conducted with the MS-TAQ questionnaire, as well as our own study, did not reveal differences in the DMT-SE domain between adherent and nonadherent patients. However, the analysis of individual questions showed that in the DMT-SE domain, nonadherent patients significantly more frequently reported the presence of swelling, stinging, or burning at the drug administration site $(P=0.0165)$ and abnormal skin reddening or rash at the injection site after the administration of treatment $(P=0.0106)$ compared with adherent patients.

The present study showed that half of the patients were satisfied or very satisfied with their treatment, whereas other authors ${ }^{27}$ have indicated that over $80 \%$ of patients perceived treatment as beneficial. A study by Glanz et $\mathrm{al}^{28}$ showed that for injections of interferon beta-1a administered subcutaneously, convenience and overall satisfaction with treatment were associated with decreased adherence. However, in our own study, there were no statistically significant differences in the degree of patient satisfaction among adherent and nonadherent patients.

In 2002 , the $\mathrm{WHO}^{9}$ drew attention to the issues of adherence in chronic diseases as one of the most important components of therapeutic management. Therefore, conducting further studies to determine the degree of adherence among MS patients is extremely important in terms of the use of effective therapy. This therapy is a heavy burden to the patient due to the long-term character and the incidence of side effects. The present study is the first in Poland to assess the level of adherence among MS patients treated with firstline immunomodulatory drugs. In the future, studies identifying factors that reduce adherence as well as factors that can positively influence the patient and mitigate difficulties with the treatment regimen should also be undertaken.

This study has some limitations. First, the self-report questionnaire was used to determine the degree of adherence and is thus a subjective instrument. Second, although the selection of patients was random and the study was anonymous, only people who followed the recommendations could participate in the study. Third, definition of adherence in our study was described directly as not missing any doses during 28 days so this period of time might be too short to show any missed injections for medications dosed with larger intervals (eg, Avonex). And the last, this study did not measure barriers to adherence in oral medications, which should be taken into account in the future studies.

\section{Conclusions}

The degree of adherence among MS patients treated with immunomodulatory drugs is high; however, some patients do not take medications regularly. By using the MS-TAQ, caregivers of MS patients are able to quickly and easily assess the occurrence of side effects, ways to cope with them, and the occurrence of barriers to taking medication.

\section{Data availability}

The authors confirm that all data underlying the findings described in this manuscript are fully available to all interested researchers upon request.

\section{Ethics approval}

The study protocol was approved by the Independent Bioethics Committee of the Wroclaw Medical University (decision number KB-444/2016). All participants gave written informed consent after thorough explanation of the 
procedures involved. The study was carried out in accordance with the tenets of the Declaration of Helsinki.

\section{Acknowledgments}

There were no other contributors to the article than the authors as well as there was no writing assistance required. The certificated English language services were provided by an academic highly qualified native English speaker to ensure a proper language quality including syntax, spelling, and grammar issues. This study was funded by the Ministry of Science and Higher Education in Poland as a grant for young researchers at the Wroclaw Medical University (no STM.E025.16.041).

\section{Disclosure}

The authors report no conflicts of interest in this work.

\section{References}

1. Leray E, Moreau T, Fromont A, Edan G. Epidemiology of multiple sclerosis. Rev Neurol. 2016;172(1):3-13.

2. Brola W, Fudala M, Flaga S, Ryglewicz D, Potemkowski A. Polski rejestr chorych na stwardnienie rozsiane - stan obecny, perspektywy i problemy [Polish registry of multiple sclerosis patients - current status, perspectives and problems]. Aktualn Neurolo. 2015;15(2):68-73. Polish.

3. Brozek P, Brachmanska M, Rabiczko K, Bulska W, Ciulkowicz M, Krzystanek E. Depression, sleep disturbances and anxiety in patients with relapsing-remitting multiple sclerosis: a longitudinal cohort observation. Psychiatr Danub. 2017;29(Suppl 3):464-468.

4. Browne P, Chandraratna D, Angood C, et al. Atlas of Multiple Sclerosis 2013: A growing global problem with widespread inequity. Neurology. 2014;83(11):1022-1024.

5. Arroyo E, Grau C, Ramo C, Parra J, Sánchez-Soliño O, por el grupo espanol del estudio GAP. Global adherence project to disease-modifying therapies in patients with relapsing multiple sclerosis: 2-year interim results. Neurologia. 2010;25(7):435-442.

6. di Battista G, Bertolotto A, Gasperini C, Ghezzi A, Maimone D, Solaro C. Multiple Sclerosis State of the Art (SMART): a qualitative and quantitative analysis of therapy's adherence, hospital reliability's perception, and services provided quality. Mult Scler Int. 2014;2014(3): $1-9$.

7. Ožura A, Kovač L, Sega S. Adherence to disease-modifying therapies and attitudes regarding disease in patients with multiple sclerosis. Clin Neurol Neurosurg. 2013;115:S6-S11.

8. Decoo D, Vokaer M. Treatment adherence in multiple sclerosis: a survey of Belgian neurologists. Patient Prefer Adherence. 2015;9: 1669-1676.

9. World Health Organization. Innovative Care for Chronic Conditions: Building Blocks for Action: Global Reports. Geneva, Switzerland: WHO; 2002.

10. Wicks P, Massagli M, Kulkarni A, Dastani H. Use of an online community to develop patient-reported outcome instruments: the Multiple Sclerosis Treatment Adherence Questionnaire (MS-TAQ). J Med Internet Res. 2011;13(1):e12.

11. Evans C, Marrie RA, Zhu F, et al. Adherence to disease-modifying therapies for multiple sclerosis and subsequent hospitalizations: MS adherence and hospitalizations. Pharmacoepidemiol Drug Saf. 2017; 26(6):702-711.
12. Burks J, Marshall TS, Ye X. Adherence to disease-modifying therapies and its impact on relapse, health resource utilization, and costs among patients with multiple sclerosis. Clin Outcomes Res. 2017; 9:251-260.

13. Mckay KA, Tremlett H, Patten SB, et al. Determinants of non-adherence to disease-modifying therapies in multiple sclerosis: A cross-Canada prospective study. Mult Scler J. 2017;23(4):588-596.

14. Beer K, Müller M, Hew-Winzeler AM, et al. The prevalence of injection-site reactions with disease-modifying therapies and their effect on adherence in patients with multiple sclerosis: an observational study. BMC Neurol. 2011;11(1):144.

15. Devonshire V, Lapierre Y, Macdonell R, et al. The Global Adherence Project (GAP): a multicenter observational study on adherence to disease-modifying therapies in patients with relapsing-remitting multiple sclerosis. Eur J Neurol. 2011;18(1):69-77.

16. Roudbary S-A, Yousefzadeh-Chabok S, Behzadnia H, et al. Nonadherence to disease-modifying treatments in patients with multiple sclerosis. Casp J Neurol Sci. 2017;3(10):128-134.

17. Hansen K, Schüssel K, Kieble M, et al. Adherence to disease modifying drugs among patients with multiple sclerosis in Germany: a retrospective cohort study. PLoS One. 2015;10(7):e0133279.

18. Evans C, Marrie RA, Zhu F, et al. Adherence and persistence to drug therapies for multiple sclerosis: A population-based study. Mult Scler Relat Disord. 2016;8:78-85.

19. PatientsLikeMe. Polish version of MS-TAQ questionnaire. Available from: https://www.openresearchexchange.com/public/library/ instruments/30/overview. Accessed September 2, 2017. Polish.

20. Cramer JA, Roy A, Burrell A, et al. Medication compliance and persistence: terminology and definitions. Value Health. 2008;11(1):44-47.

21. Higuera L, Carlin CS, Anderson S. Adherence to disease-modifying therapies for multiple sclerosis. J Manag Care Spec Pharm. 2016;22(12): 1394-1401.

22. Halpern R, Agarwal S, Dembek C, Borton L, Lopez-Bresnahan M. Comparison of adherence and persistence among multiple sclerosis patients treated with disease-modifying therapies: a retrospective administrative claims analysis. Patient Prefer Adherence. 2011;5:73-84.

23. Mikol D, Lopez-Bresnahan M, Taraskiewicz S, Chang P, Rangnow J; Rebiject Study Group. A randomized, multicentre, open-label, parallelgroup trial of the tolerability of interferon beta-1a (Rebif) administered by autoinjection or manual injection in relapsing-remitting multiple sclerosis. Mult Scler. 2005;11(5):585-591.

24. Poorjavad M, Derakhshandeh F, Etemadifar M, Soleymani B, Minagar A, Maghzi AH. Oropharyngeal dysphagia in multiple sclerosis. Mult Scler J. 2010;16(3):362-365.

25. Fernandes AM, Duprat AC, Eckley CA, Silva L, Ferreira RB, Tilbery CP. Oropharyngeal dysphagia in patients with multiple sclerosis: do the disease classification scales reflect dysphagia severity? Braz J Otorhinolaryngol. 2013;79(4):460-465.

26. Köşkderelioğlu A, Gedizlioğlu M, Ortan P, Öcek Ö. Evaluation of the adherence to immunmodulatory treatment in patients with multiple sclerosis. Noro Psikiyatr Ars. 2015;52(4):376-379.

27. Spessotto CV, Cavalli H, Eboni AC, et al. Patients' satisfaction with and views about treatment with disease-modifying drugs in multiple sclerosis. Arq Neuropsiquiatr. 2016;74(8):617-620.

28. Glanz BI, Musallam A, Rintell DJ, Chitnis T, Weiner HL, Healy BC Treatment satisfaction in multiple sclerosis. Int J MS Care. 2014; 16(2):68-75. 
Patient Preference and Adherence

Dovepress

\section{Publish your work in this journal}

Patient Preference and Adherence is an international, peer-reviewed, open access journal that focuses on the growing importance of patient preference and adherence throughout the therapeutic continuum. Patient satisfaction, acceptability, quality of life, compliance, persistence and their role in developing new therapeutic modalities and compounds to optimize

clinical outcomes for existing disease states are major areas of interest for the journal. This journal has been accepted for indexing on PubMed Central. The manuscript management system is completely online and includes a very quick and fair peer-review system, which is all easy to use. Visit http://www. dovepress.com/testimonials.php to read real quotes from published authors.

Submit your manuscript here: http://www.dovepress.com/patient-preference-and-adherence-journal 